\title{
Causes and Sources of Waste in the Printing Industry in Ghana: A Study of Printing Houses in the Cities of Accra and Kumasi
}

\author{
Ashford C. Chea \\ School of Business, Stillman College \\ $19258^{\text {th }}$ Ave. $\# 12 \mathrm{H}$ \\ Tuscaloosa, AL 35401, U.S.A \\ Tel: 1-205-366-8829 E-mail: achea@ix.netcom.com
}

\begin{abstract}
This study was undertaken in the summer of 2006 to identify the causes of waste in the printing houses in two major cities in Ghana, namely, Accra and Kumasi. The scope of the study was limited to printing houses operating in the above cities only. The relevant literature on offset lithographic printing, the categories and causes of waste, and its effects on the environment were reviewed. The method used in gathering data for the study consisted of questionnaires that were sent out to fifty-five printing houses in Accra and Kumasi. Forty-seven printing houses responded to the questionnaires. The data were thoroughly analyzed and, where necessary, presented in tables. Finally, findings are discussed, implications outlined, recommendations and areas of future research proposed, and conclusion drawn.
\end{abstract}

Keywords: Ghana, Industry, Printing, Houses, Waste, Environment

\section{Introduction}

The problem of spoilage and waste control in the printing industry in Ghana cannot be overemphasized. It had been discussed in workshops and seminars. Observation showed that waste created in printing houses in the cities of Accra and Kumasi was enormous-a lot of papers, inks, darkroom chemicals, films, and plates. The practice has become a normal trend for the employees and management of these printing houses, without realizing the effect waste poses on the customers, the company, the environment, and the Ghanaian society as a whole. The quantity of waste created affects the production cost, and its disposal poses a threat to the environment. In Ghana, the disposal of printing waste doesn't cost printing houses financially. Even though there are laws governing the proper disposal of waste, these laws are not enforced. Since there are no stringent penalties for improper disposal of waste and spoilage, printing houses dispose of their waste anyway - in gutters, in dumpsters, in rivers, and on the land. This study was taken during the summer of 2006 to investigate the causes of excessive waste/spoilage generated in printing houses in the cities of Accra and Kumasi in Ghana.

\section{Objective and Scope of the Study}

The objective of this study was to identify the causes and sources of waste in the printing houses in the Ghanaian cities of Accra and Kumasi. The scope of this study was limited to the causes and reduction of spoilage and waste in the printing industry in Ghana. The study involved forty-seven (47) printing houses in the cities of Accra and Kumasi. It primarily focused on the causes of spoilage of materials such as papers, ink, plates, and chemicals. The research question was: What material is the greatest contributor to waste generated in printing firms in the cities of Accra and Kumasi?

\section{Literature Review}

Waste is defined as something lying unproductive, inhabited, or desolate. Generally all waste appears in three forms, namely: solid waste, wastewater (liquid waste), and air emission (Appiah, 2002). Waste reduction which is vital to the growth and development of printing houses in Ghana cannot be overemphasized. In order to run a printing house as economically and efficiently as possible, one should reduce all types of wastes including hazardous wastes, solid wastes, and air and water emissions. Waste generation is inevitable in printing industry. All the printing processes, namely, offset lithographic printing, gravure printing, flexography/letterpress, and screen printing use materials and chemicals that generate waste. When the waste generated causes financial loss to a company and poses a threat to the environment-air, water, and land, then it becomes a problem to society at large. This study reviews literature on waste generation and reduction in offset lithographic printing. 


\subsection{The Printing Industry}

The printing industry uses various printing technologies for printing books, magazine, newspapers, business documents, catalogs, form, etc. These technologies include lithography, rotogravure, flexography, screen, letter-press, and digital technologies including inkjet and electro-photography. The use of these technologies depends on the required quality of the print, number of impressions to be printed, availability of required resources, cost of the equipment, consumables cost per unit, need to use variable content, and other factor (Romano, 2004).

\subsubsection{Overview of Offset Lithographic Printing}

Offset lithographic printing is the predominant process used in printing today. In the United States, it is currently the most prevalent printing technology. According to an estimate by A.F. Lewis \& Co., a market research firm specializing in the graphic arts industry, there are over 53,000 establishments employing the printing process, and approximately 49,000 of these use lithographic presses. Lithographic printing is likely to remain a viable technology for the long term for static, long run jobs either as a standalone technology or as a component of hybrid production (Romano, 2003). Digital color printing is poised to grow significantly over the next five years with the primary growth driver being cost reduction (Dalessandro, 2001). In Ghana, a survey of forty-seven (47) presses in the cities of Accra and Kumasi conducted by the author of this study shows that all of the printing houses use lithographic presses. The success of the lithographic printing is due to the ability of the process to produce high quality text and illustrations cheaply and effectively in short, medium, and high volume production runs.

Lithography is used for a wide range of items from letterheads to books and magazines. Some other applications of the lithographic printing process include advertising, envelops, labels and tags, stationery, greeting cards, and packaging. However, the ascendancy of the lithographic process may soon be challenged by both improvements in flexography and relatively new plate-less technologies, which make up the fastest growing sector of the printing industry in both developing and developed countries (Hird, 1991).

\subsubsection{Types of Lithography}

The lithographic printing is divided into three separate sub-processes: sheet fed offset, heat set web offset, and non-heat set web offset. Sheetfed presses refer to presses designed to print a single sheet of paper at a time. They are built to pick up individual sheets of paper from a feed table. Sheets are delivered equally, one at a time down a feedboard to the printing unit (Appiah, 2002). Sheetfed presses constitute the majority of presses in offset lithographic printing. The web offset presses are so named because of their use of rolls of paper which are continuously fed into the press. Only a few of lithographers use the web offset process. In heatset web offset printing, inks are dried using a recirculating hot air system. This type of printing is very useful for high-volume, high-speed production runs (up to 40,000) impressions per hour); however, the ink drying process involved may result in volatile organic compound (VOC) emissions that must be controlled. In contrast, non-heatset web offset process often uses inks that do not require assisted drying. Each of these sub-processes has some distinct environmental and human health impact (Romano, 2003).

\subsubsection{Classification of Waste}

It is important to note that waste do differ from process to process and the methods of reducing waste in one printing process do not necessarily apply to other printing processes. There are three major waste streams found in the printing industry. They include: (a) solid waste - in general printing environment solid waste could consist of the following: empty containers, used film packages, outdated materials, damaged plates, developed films, dated materials, test production, bad printing or spoilage, damaged product, and scrap papers (b) water waste - water waste from printing operations may contain lubricating oils, waste ink, clean-up solvents, photographic chemicals, acids, alkaline, and plate coatings, as well as metals such as silver, iron, chromium, copper, and barium and (c) air emissions - printing operations produce volatile organic compound emissions from the use of cleaning solvents and inks, as well as alcohol and other wetting agents used in lithographic printing. Larger plants can be the source of sulfur dioxide emissions (Lewis, 1982). Finishing operations may include final trimming, die cutting, folding, collating, binding, laminating, embossing, and assembling operations. Binding methods include stitching (stapling), gluing, and mechanical binding. The primary waste are binding and laminating chemicals and scrap papers (Banerjee, 2001).

\subsubsection{Waste and the Environment}

An awareness of environmental, health, and safety issues plays an important role in the identification of printing technologies. Lithographic printers may not be familiar with available government-supported environmental information programs, and may rely primarily on vendors, suppliers, customers and trade association for such information (Rothenberg, Toribio, and Becker, 2002).

Printing operations use materials that may adversely affect air, water, and land resources: certain chemicals involved in printing volatilize, which contributes to air emissions from the facility and to smog formation; other chemicals may be discharged to drains and impact freshwater or marine ecosystem; and solid waste contribute to the existing local and 
regional disposal problems. There is a growing concern in Ghana about industrial waste and pollution, health and safety hazards to industrial workers, public health problems due to adverse environmental changes and the misapplication of hazardous chemicals. Atmospheric pollution associated with Ghana's industrialization activities result mainly from combustion processes. These pollutants tend to be in the form of particulate matter, smog, odor, and nuisance gases. These emissions contain varying amounts of gases such as nitrogen, hydrocarbons, and carbon. Apart from the health problems caused by these gases, they also contribute to the problem of acid rain. In recent years, hydrocarbons have been identified as substances contributing to the global ozone depletion problem (Tilley, 1999).

In the printing industry inks such as web offset heatset and non-heatset inks contain hydrocarbons in their formulation. The improper disposal of fixer, for instance, can be very harmful to the environment. The disposal of fixer is a big problem for the environment (Appiah, 2002).

\section{Method}

The method used in carrying out the study includes both primary and secondary sources of information gathering. Books, articles, and relevant documents were reviewed to help carry out this study. Structured questionnaires were used as instruments to solicit vital data. Questionnaires were used due to the large number of printing houses and time constraint. The questionnaires were distributed to fifty-five (55) printing houses in Accra and Kumasi.

\subsection{Sampling}

In the researcher's attempt to conduct an effective study, a population which was made up of all printing houses in Accra and Kumasi was considered. The sample size was made up of forty-seven (47) printing houses. The sample frame was chosen with the random sampling method with each printing house having not less than five employees. There are about 92 registered printing houses in Accra and Kumasi. Out of the 55 questionnaires distributed, an impressive number of 47 were retrieved. The responses were compiled, analyzed, and presented on tables. Comparisons and deductions were made and implications were drawn from the responses.

\subsection{Data Analysis}

Spoilage/wastage in a printing house cannot be done eliminated, but can readily be controlled. There are many causes of spoilage/wastage in a printing house. The data gathered will help find out from the printing houses selected, the causes of spoilage/wastage in the presses; their ways of disposal; the effects of spoilage/waste on a company and the environment. This section groups the data collected into three sub headings. These include (1) grouping the printing houses in the sample (2) causes of paper spoilage/wastage and (3) causes of film and darkroom chemicals wastage/spoilage.

The questions used in collecting the data are stated and the responses are presented in tables. Deductions, inferences, explanations, and implications are then used to analyze the responses.

\subsubsection{Grouping of Responses}

The researcher's concern was to know the categories of printing houses studied. Three questions were asked to help gather responses for the stated intention. These questions are (a) how many workers are in the company? (b) what departments do you have? and (c) what equipment, materials, and chemicals do you use? Most of the respondents refused to write the number of machines and equipment they had; for this reason, the responses from the number of employees were used as the criteria for grouping the printing houses into three groups, A, B, and C. From the responses, companies with employees numbering 61-100 and above were grouped as A. Employees numbering 21-60 were grouped as B, and employees numbering 5-20 were grouped as $\mathrm{C}$. The number of employees available in a printing house and the quantity of goods produced determined the level of waste created. From the data gathered, the level of waste created by group A is expected to be higher compared to that of group B because they have more machines and workers, and they produce more. Group B is also expected to produce a higher amount of waste/spoilage compared to that of group C. Group C is expected to produce less waste/spoilage with regard to the number of machines, and workers and the quantity of production as compared to that of groups A and B. The responses are presented in the tables 1 and 2 .

\subsubsection{Causes of Paper Wastage/Spoilage: Machines}

The working condition of the machines in the printing house is as vital as the expertise of the machine operator. All the parts of the machine are supposed to work properly if quality of work is to be achieved. The feeder board, grippers, cylinders, rollers, delivery board etc., must be in place and functioning properly to avoid the malfunctioning or the total break down of the machines during production. This calls for the regular maintenance of the machines to keep them in good condition which will help in the reduction of waste in the printing house. In view of this, the researcher asked the following question: Do you have a maintenance schedule for your machines? The answer options to the question were Yes and No. $89 \%$ of the respondents have a maintenance schedule program. $11 \%$ do not have a maintenance schedule program. It could also be that, even though they do not have a schedule for maintaining their machines, they may have 
their own way of ensuring that their machines are in good condition for work. In a bid to know if the maintenance schedule was implemented by the printing houses under study, the researcher asked accordingly. From the data, $9 \%$ had a weekly maintenance schedule program, $42 \%$ had a monthly maintenance schedule program, $28 \%$ carry out a yearly maintenance schedule program, and $21 \%$ did not choose any of the options but had their own reasons such as (a) the machines are checked daily and will therefore not need a total maintenance section (b) the machines are not faulty and so if they are tempered within the verge of maintenance, they may develop problems and (c) they may even breakdown totally due to the constant removing of screws and bolts. The responses are presented table 3 .

It is encouraging to know that some sort of maintenance is carried out on the machines of the printing houses in one way or the other. How often the schedule of the machine is carried out may depend on the efficiency or the working condition of the machine. When machines break down due to poor maintenance, production time is wasted. And when a part of the machine is faulty, papers and other materials are wasted.

\subsubsection{Spoilage Allowance (Overs) Added To Paper}

Printing on the press demands that extra sheets be added to the actual number of sheets needed for the job. This is termed as overs or spoilage allowance. Overs are added to ensure that the correct number of copies a job demands is attained. On the average, the overs on a full color job should not exceed $15 \%$, and that of a single color job should not exceed $10 \%$. If overs for a full color job and single color job exceed their average percentages, it will cause waste. The objective of the researcher was to know the percentage of overs used by the respondents. This was to verify if the respondents use the right number of overs during a press run. The data show that the average percentage of overs added to a full color job should be more than that of a single color (black and white) job. Since more sheets are needed when printing full color. The responses are presented in tables 4 and 5 .

\subsubsection{Waste Control Policy}

A waste control policy is a guiding framework within which an organization controls its waste. This policy entails the dos and don'ts that will help reduce waste in a printing house. All printing houses should have a waste management policy that will help them reduce the amount of waste produced and then monitor its disposal. To achieve this, all the workers must be aware of the policy and know their various roles in implementing it. The researcher's aim was to know if there is any printing house that does have a waste control policy. Therefore, the following question was posed: Do you have rules that govern the controlling of waste? The answer options for this question were Yes and No. $72 \%$ answered yes to the question and $28 \%$ answered no, meaning measures have not been put in place to help check waste. This means that they are likely to generate a lot of waste in their daily activities in the printing house. It could also happen that some of the printing houses have the policy, but the workers do not know about it.

Policies must be implemented to prove their existence and to solve the problems for which they were made. Having a policy alone is not good enough. It has to be implemented at a uniform level in the printing house to achieve the aim for which it was initiated. For this reason, the researcher wanted to know if the respondents implemented their policies. The answer options to this question were Yes and No. $47 \%$ of the respondents answered yes to the question, while $53 \%$ responded no to the question. It can be deduced that $25 \%$ of the respondents have rules to control waste in their printing houses but do not implement them, leaving $47 \%$ who have a policy and at the same time implement it.

\subsubsection{Quality Control}

The researcher wanted to know if the quality control unit of the various printing houses inspects the jobs as they go through the various stages in the production process. From the responses, $79 \%$ of the sample frame has a quality control unit while $8 \%$ does not have any quality control unit or system in their printing houses. $13 \%$ did not choose any of the options but gave their reasons as: There were no departments in the printing house responsible for quality control, and every individual employee who works in the printing house from pre-press, press to finishing is trained to know about quality control which they apply in the working process. This implies that a higher percentage of the respondents have quality control/assurance units, which is a good sign. $13 \%$ do not have a quality control unit, but rather, every individual employee in each section is trained for that duty. This means that they may not need a structured quality control department or unit. The quality control unit in the printing house helps to avoid the generation of waste during production.

\subsubsection{Materials with High Rate of Spoilage}

The researcher wanted to find out the most wasted material in the press. The data reveal that paper records the highest percentage of spoilage/waste. Some respondents specified that newsprint is most wasted. Ink is considered to be the second most wasted material according to $11 \%$ of the respondents. Films, darkroom chemicals, and plates made up $8 \%$ of the respondents. The fact cannot be disputed that paper is the most wasted material in the printing house. The results of this question are presented in the table 6. 


\subsubsection{Paper Storage}

Printing houses normally buy their papers in bulk and keep them in storerooms for production. Papers must be stored in a proper storeroom. That is, a well-ventilated room with cabinets, good roofs without leakage, and good windows and doors. If paper is not well-stored, it can create a lot of problems for the printer. (Dimensional problems such as humidity, crumpling of the paper, color change of paper are examples). With paper, proper storage will avoid damage from temperature, humidity, and spills as well as physical damage. On this note, the researcher's focus was to know if printers encounter difficulties printing with stored papers. The responses gathered revealed that $32 \%$ encounter some difficulties when printing with stored papers, but $62 \%$ do not encounter difficulties in printing with stored papers. $6 \%$ did not choose any option. The $62 \%$ of the respondents that do not encounter problems when printing is quite encouraging. This is because if difficulties are not encountered, then waste is avoided. $32 \%$ of the respondents encounter difficulties when using stored papers because their papers are not properly stored.

\subsubsection{Temperature}

Paper is delivered in sealed packs; the temperature of the pack or the storeroom can be different. If a paper with a different temperature is exposed to the press room atmosphere, it will change the temperature of the air surrounding the stack and alter the surrounding humidity. If the relative humidity surrounding the stack is higher than the moisture content of the paper the edges of the stack will absorb moisture until it reaches the level of equilibrium. This can cause the paper to curl or have wavy edges.

If the relative humidity surrounding the stack is lower than the moisture content of the stack, the edges will release moisture into the atmosphere producing tight edged papers. Printing with wavy edge or tight edge paper generates a lot of waste. In view of this, the researcher asked the following question: Is the temperature in the pressroom the same as that of the storeroom? The answer options for the question were: Always, Never, or Sometimes. The data collected show that $34 \%$ of the respondents said their pressroom temperature is always the same as the storeroom temperature. $32 \%$ said the temperature is never the same. $26 \%$ said the temperature is sometimes the same, and $8 \%$ gave no response. Those who responded that their pressroom temperature is always the same as the storeroom will not have problems when printing with stored papers. It would not even be necessary to condition the papers before printing. Those who said it is never the same are likely to generate a lot of waste when printing with stored papers if they do not condition the papers. The $26 \%$ who said the temperature is sometimes the same are likely to generate waste as well if they do not condition their paper before printing on it. This is because a change in temperature can occur at anytime. To avoid wasting paper, it has to be conditioned all the time.

\subsubsection{Paper Conditioning}

This is a term given to the process of allowing paper to adjust to the temperature or the humidity of a given area. The greatest enemy of paper in the press is temperature. Changes in humidity cause changes in the paper's properties. The physical properties of paper are affected by moisture to some extent. The one that concerns printing houses most is dimensional stability, which relates to changes in size and shape of the paper. Sheets that have wavy edges and tight edges are difficult to feed through the gripper system which can cause papers to crease on the press and destroy the blanket. The problems mentioned above accounts much of the waste in the printing house. The only way this can be reduced is for printers to condition paper before it is used. In view of this, the researcher wanted to find out if the respondents condition the paper before using it, and therefore asked the following question: Are sheets of paper conditioned before use? The answer options were Always, Never, and Sometimes. The responses to this question reveal that $21 \%$ of the subjects always condition their papers before using them. $17 \%$ never condition their paper before using it. $53 \%$ sometimes condition their paper before using it, and $9 \%$ did not respond. The $21 \%$ who always condition their paper before printing are engaged in a very good practice, which will help them in reducing paper waste to the minimum. It is obvious the $53 \%$ are not ignorant of the practice. They sometimes ignore the practice due to pressure on the press floor, which forces them to print within a very short notice, without conditioning the papers. The $17 \%$ who never condition their papers may have the temperature in both the pressroom and the storeroom being the same. Therefore it becomes unnecessary to condition paper.

It is a bad practice to print on sheets of paper without conditioning them. This is because it can lead to the generation of a lot of waste. Conditioning the paper is also very important. Some printers allow just a short time for paper to condition when it is brought to the press. The standard time limit for a paper to condition is 24 hours.

If the temperature in the pressroom and the storeroom are almost the same, the papers can adjust in just a short time. Therefore, it is always advisable to allow at least one hour for paper conditioning before safe printing. If paper is conditioned for less than an hour, it is likely to have dimension stability like tight edges, wavy edges or poor feeding. This causes a lot of paper spoilage during printing. Some other problems that cause paper spoilage are as follows: (a) bad weather conditions and (b) discolored paper. 


\subsubsection{Causes of Plate Waste/Spoilage}

The research revealed that $8 \%$ of printing plates were processed in house, whereas $11 \%$ were done outside. The concern of the researcher, however, was to establish the various complications that are associated with plate processing, and that are likely to cause waste or spoilage. To this end, the respondents were asked to state complications in plate usage. The data show that $30 \%$ of the respondents encountered the problem of over exposure, $26 \%$ had the problem of under exposure, and $28 \%$ encountered problems due to weak chemicals. $16 \%$ did not choose any of the options. In addition to the options chosen, some respondents added other problems that can cause plate wastage/spoilage. These include (a) expired plates sold out to printer (b) poor stripping (c) outdated or expired plates (d) improper application of chemicals (e) unstable electricity current, and (f) faulty plate making machine. The data presented imply that printers develop one problem or the other when developing plates. Under exposure occurs when the light source for plate burning is not strong enough or when the required time for developing the plate is not reached. Images on this plate cannot be made sharp for printing and must be discarded. $30 \%$ also faced the problem of over exposure. When plates are over exposed, the images get distorted and the plate cannot be used in printing. Nothing can be done to reverse this effect and the plates therefore go to waste. After plates have been exposed, they are developed with chemicals. The chemicals are negative and positive plate developers. If these chemicals are not strong enough to remove all the coatings on the plate to make the image sharp the plate will not be suitable for use. This causes the plates to go to waste.

\subsubsection{Plate Storage}

If plates are not well stored, they may get destroyed at any time, because they are very sensitive to light, water, and scratches. The researcher's aim was to find out the causes of plate wastage/spoilage during storage and if plates are reused or discarded after production. For this reason, the researcher asked the following question: Are plates stored and reused? The answer options were Yes and No. The data show that $72 \%$ of the respondents said they store their plates and reuse them, and $11 \%$ do not store their plates. $17 \%$ did not choose any option. The information implies that $72 \%$ store their plates with preservatives and use them again when needed. Some printers encounter problems when using stored plates. The preservatives sometimes get stuck to the plates and will not come off. $11 \%$ do not store their plates at all. They make new ones whenever they need to do a re-print. This happens especially with newspaper and magazine printers. This practice costs a company a lot of money since it will have to make a new plate for every re-print. The old plates go to waste. The data gathered are presented in Table 7.

The researcher wanted to know why stored plates sometimes go waste. He therefore asked the following question: "Do stored plates go to waste?" If yes, what amounts to the waste? The following options were given: (a) Poor storage (b) Outlive their number of impressions and (c) Others. The responses show that $19 \%$ said plates go waste due to poor storage. $32 \%$ also admitted that plates outlive their number of impressions, and $28 \%$ gave their own reasons why plates go to waste in their printing houses: These include, for example, a publisher seeking a re-printing of a previously printed work, and changes such as changes in pages and dates are to be made. Other instances involve bad storage conditions and temperature, and the use of too much deleting fluid on the plates. When plates are stored in a damp place, oxygen will act on the plate causing the plates to rust. Plates are made to only withstand a certain number of impressions after which they become unsuitable for reuse. When a plate outlives its number of impressions, it becomes unsuitable for reuse. The responses to this question are presented in the table 8 .

\subsubsection{Disposal of Waste by Printing Houses and Its Effect on the Environment}

Wastes created in the printing house must be disposed of. The disposal methods can cause a serious threat to the environment and human life. It is the social responsibility of the company to make its surrounding community a pollution-free environment. The researcher wanted to know how the wastes created by the printing houses were disposed of. In view of this, the question below was asked. How are the following waste materials disposed of: paper, ink, plate, films/darkroom chemicals? The results show that $67 \%$ of the sample frame burn their waste papers. $21 \%$ sell them to paper-making companies, $10 \%$ dump them in the dumpster, and $2 \%$ did not choose any of the options. $39 \%$ of the respondents pour their ink waste into the drains. $36 \%$ keep them in containers for reuse, and $20 \%$ burn their ink waste. $79 \%$ of the respondents sell their waste plates to the local aluminum pot makers. $11 \%$ use them for items such as calendar, while $6 \%$ throw them away. $74 \%$ of the respondents burn their waste films, while $26 \%$ throw them away. The responses also show that $67 \%$ pour their waste darkroom chemicals into the drains. $23 \%$ pour them away anywhere outside the printing house, and $10 \%$ did not choose any option. The statistics presented above shows that most of the methods used by the printing houses in disposing of the waste generated are not environmentally friendly.

\section{Summary of Findings}

The following findings were derived from this study. The study revealed that a good number of the printing houses had maintenance schedule programs and just a small number of them did not have them, but they had other ways of making certain that their machines are in good condition for use. It is established that a high percentage of the respondents had a waste control policy, but some of them did not implement it. The research again revealed that a 
large number of the respondents have a quality control unit. Others do not have a structured department/section assigned for checking quality but have trained all their employees in the area. There were some who did not have a unit for quality control at all.

It is established in this study that paper is the most wasted material in the printing houses followed by ink, plate, films, darkroom and chemicals. It is also established that many printing houses do not encounter difficulties in printing with stored papers. Just a few printing houses face problems when printing with stored papers because they do not carry out paper conditioning practices, or they go about it in the wrong way. It was discovered that a large percentage of the respondents admitted the temperature of their storeroom is the same as the pressroom.

Another finding was that the plates are stored with preservatives and reused.

A majority of the respondents process their plate in-house. Some printing houses do not store their plates and reuse them, but make new ones when needed. Storage of unused or new plates does not cause very much waste compared to already processed plates because workers pay more attention to the proper storage of new plates. It was discovered that a majority of the printing houses determine the quantity of ink needed for a job by estimates. Others also determine the ink needed by experience. Finally the research unveiled the fact that the methods of disposal adopted by printing houses studied were not environmentally friendly. In terms of the limitation of the study, the researcher couldn't cover a wider area in the population due to the lack of time.

\section{Recommendations and Managerial Implications}

Companies can use a variety of ways to reduce the amount of waste they generate while increasing their operational efficiency. Best management practices (BMPs) create the most cost-effective way to decrease the amount of waste generated from operations. BMPs require building an employee commitment and interest in waste prevention, as well as managerial support, to encourage participation in waste prevention programs. This includes a careful control of raw materials, practical scheduling, and job management. Other potential hazardous waste reduction techniques for printing houses require good housekeeping. Good housekeeping measures can greatly decrease the amount of waste that a firm generates. For example, a good housekeeping and maintenance program can help to ensure that all machinery and processes are working well with no leaking valves and tanks. Similarly, to reduce excess waste production, printing houses should: (a) Make sure container lids are tight fitting whenever they are not in use to prevent loss of chemical through evaporation or spoilage. Keeping lids on containers also prevents contamination with water, dirt, or other materials (b) Use spigots and pumps when dispensing new materials and funnels when transferring waste to storage containers to reduce the possibility of spills (c) Store products in locations that will preserve their shelf life. For instance, solvents should be kept in locations protected from extreme temperatures (d) Never mix different types of waste together. Mixing wastes may make recycling impossible or make waste disposal more expensive and (e) keep printing houses clean and orderly to prevent accidents and spills.

Several implications for managers were drawn from this study. First, managers need to train their employees in the proper operation of printing equipments to minimize waste created through misuse, and ensure that all employees are aware of and are familiar with company waste reduction programs, policies, and objectives. Second, managers need to set up an employee waste reduction committee. Third, they need to order and manage materials to minimize inventory going out of date and becoming a waste. Fourth, management should implement a first-in first-out inventory policy for materials with a limited shelf life. Fifth, managers should inspect all materials received and off-specification or damaged materials should be returned immediately to vendors. Sixth, they should store ink according to manufacturer instructions to prevent skinning and drying, and ink should be kept in locations that will preserve its shelf life. Finally, managers should centralize responsibility for storing and distributing solvents.

This study also has an implication for the literature on waste management in the printing industry, particularly regarding the adoption of waste management practices such as best management practices and good housekeeping standards. This study likewise contributes to previous research on waste management in the printing industry in Ghana. Prior research had used an in-depth qualitative case study to explore the effectiveness of a firm's waste management approach. In this current study, the researcher took a different approach by using a larger sample of printing houses and a quantitative approach to assess and analyze the causes and sources of waste in printing houses in Ghana.

\section{Areas for Future Research}

An important task for future research would be to further examine the relationship between different forms of waste and their impact on the environment. Future research might also continue to explore the alternative waste management strategies and their effects on printing houses' operating costs and profitability. Another promising avenue for further study would be to expand the study of waste generation in printing houses to include firms in other cities in Ghana.

\section{Conclusion}

Waste in the printing houses, as stated earlier, can be controlled but cannot be totally eliminated. Refusing to control 
the waste generated in a printing house means that production costs will rise, customers will drift, the company's profit will reduce drastically, and the environment will be polluted. The findings of this research reveal that a lot of waste is being created in printing houses, some of which can be prevented or reduced if workers make a conscious effort to manage printing waste

\section{References}

Appiah, I. K. (2002). Printing techniques. Kumasi, Ghana: Kwame Nkrumah. University of Science \& Technology Publishing.

Banerjee, S. B. (2001). Managerial perceptions of corporate environmentalism: Interpretations from industry and strategic implications for organizations. Journal of Management Studies, 38, 489-513.

Dalessandro, W. (2001). Critical issues in strategic corporate environmental management. Arlington, MA: Business and the Environment, Cutter Information Corp.

Hird, K. F. (1991). Offset Lithographic Technology. Tinley Park, Ill: Goodheart-Willcox Company, Inc.

Lewis, P. V. (1982). Managing Human Relations. Boston, MA: Kent Publishing Company.

Romano, F. (2003). The state of printing in the United States. Electronic Publishing, 27:12.

Romano, F. (2004). An investigation into printing industry trends (PICRM-2004-01). Rochester, NY: Rochester Institute of Technology, Printing Industry Center.

Rothenberg, S., Toribia, R. \& Becker, M. (2002). Environmental management in lithographic printing (PICRM-2002-07). Rochester, NY: Rochester Institute of Technology, Printing Industry Center.

Tilley, F. (1999). The gap between the environmental attitude and the environmental behavior of small firms. Business Strategy and the Environment, 8, 238-248.

Table 1. The Number of Employees in the Printing Houses

\begin{tabular}{|c|c|c|}
\hline Number of Employees & Number of Respondents & Percentage \\
\hline $5-10$ & 17 & $36 \%$ \\
$11-20$ & 7 & $15 \%$ \\
$21-40$ & 10 & $21 \%$ \\
$41-60$ & 6 & $13 \%$ \\
$61-100$ & 3 & $6 \%$ \\
101 and above & 4 & $9 \%$ \\
\hline Total & 47 & $100 \%$ \\
\hline
\end{tabular}

Table 2. The Number of Printing Houses in Each Group

\begin{tabular}{|c|c|c|}
\hline Groups & Number & Percentage \\
\hline A & 7 & $15 \%$ \\
B & 16 & $34 \%$ \\
C & 24 & $51 \%$ \\
\hline Total & 47 & $100 \%$ \\
\hline
\end{tabular}


Table 3. Implementation of the Maintenance Schedule

\begin{tabular}{|c|c|c|}
\hline Options & Number of Respondents & Percentage \\
\hline Weekly & 4 & $9 \%$ \\
Monthly & 20 & $42 \%$ \\
Yearly & 13 & $28 \%$ \\
Others & 10 & $21 \%$ \\
\hline Total & 47 & $100 \%$ \\
\hline
\end{tabular}

Table 4. Percentage of Overs on Full Color Jobs

\begin{tabular}{|c|c|c|}
\hline Range Of Overs & Respondents & Percentage \\
\hline $1-5$ & 14 & $30 \%$ \\
$6-10$ & 16 & $34 \%$ \\
$11-15$ & 6 & $13 \%$ \\
$16-20$ & 4 & $8 \%$ \\
Others & 7 & $15 \%$ \\
\hline Total & 47 & $100 \%$ \\
\hline
\end{tabular}

Table 5. Percentage of Overs on Single Color Job

\begin{tabular}{|c|c|c|}
\hline Range of Overs & Respondents & Percentage \\
\hline $1-5$ & 30 & $64 \%$ \\
$6-10$ & 8 & $17 \%$ \\
$11-15$ & 0 & $0 \%$ \\
$16-20$ & 0 & $0 \%$ \\
None & 9 & $19 \%$ \\
\hline Total & 47 & $100 \%$ \\
\hline
\end{tabular}

Table 6. Materials with High Rate of Spoilage

\begin{tabular}{|c|c|c|}
\hline Option & Respondent & Percentage \\
\hline Paper & 35 & $75 \%$ \\
Plate & 3 & $6 \%$ \\
Ink & 5 & $11 \%$ \\
Films and darkroom \\
chemicals
\end{tabular}


Table 7. Reusing Stored Plates

\begin{tabular}{|c|c|c|}
\hline Options & Respondents & Percentage \\
\hline Yes & 31 & $72 \%$ \\
No & 5 & $11 \%$ \\
None & 8 & $17 \%$ \\
\hline Total & 47 & $100 \%$ \\
\hline
\end{tabular}

Table 8. Causes of Plate Spoilage/Wastage

\begin{tabular}{|c|c|c|}
\hline Options & Respondents & Percentage \\
\hline Poor storage & 9 & $19 \%$ \\
$\begin{array}{c}\text { Outlive the number of } \\
\text { impressions } \\
\text { Others }\end{array}$ & 15 & $32 \%$ \\
None & 13 & $28 \%$ \\
\hline Total & 10 & $21 \%$ \\
\hline
\end{tabular}

